\title{
SEVERE OPTOCHIASMATIC ARACHNOIDITIS AFTER RUPTURE OF AN INTERNAL CAROTID ARTERY ANEURYSM
}

\author{
RICARDO RAMINA - WALTER O. ARRUDA**-ANTONIO C.F. PRESTES* \\ MONICA K, F. PAROLIM ***:
}

\begin{abstract}
SUMMARY - The case of a 24-year-old man with progressive visual loss due to optrochiasmatic arachnoiditis is presented. The cause of the arachnotditis was subarachnoidal bleeding due to rupture of an internal carotid artery aneurysm. The aneurysm was clipped 5 years after the first episode of bleeding. The diagnosis of optochiasmatic arachnoiditis was confirmed during the operation. This case is presented in order to discuss the causes, the symptoms and the therapeutical nossibilities of this rare condition.
\end{abstract}

Aracnoidite optoquiasmática grave após ruptura de aneurisma da artéría carótida interna.

RESUMO - Relato do caso de paciente masculino com 24 anos de idade, com perda progressiva da visão devida a aracnoidite optoquiasmática. A causa da arácnoidite foi ruptura de aneurisma da parede dorsal da artéria carótida interna direita, com hemorragia subaracnóidea. $O$ aneurisma foi clipado 5 anos após o primeiro episód.o de sangramento. O diagnóstico de aracnoidite optoquiasmática foi confirmado durante cirurgia. A fina'idade do relato é rever e discutir as causas, o quadro clínico e as possibilidades terapêt cas dessa condiçāo rara,

Optochiasmatic arachnoiditis is an unusual inflammatory disease at the base of the skull 4,18. The diagnosis is difficult in the majority of the cases and it is based on the history of the patient and the surgical findings. If a correct diagnosis is not made soon the patient may become blind.

We describe the case of a man with progressive bilateral visual loss due to an optochiasmatic arachnoiditis caused by the rupture of an internal carotid aneurysm.

\section{CASE REPORT}

JRM, a 24-year-old man presented severe headaches and epileptic fits 5 years prioi to admission to our clinic. He remained unconscious during some hours. This was his first cpileptic episode and he started to complain of headaches and progressive visual loss since then. Seven months later he was admitted to another hospital for investigation of the headaches and the visual disturbances. At that admission a severe bilaterai visual loss with papiledema was observed. Angiographic studies of both carot d arteries were performed and disclosed bilateral subdural hematoma over both fronto-parietal hemispheres. The hematonas were evacuated through frontal burr holes. After this operation the headaches improved, but the visual acuity showed progressive impairment. The patient became blind

Unidade de Ciências Neurológicas, Hospital São Vicente: "Neurocirurgıão; Neurologista, bolsista do CNPq: *** Neurologista. 
two months after the operation. On May 22, 1986 the patient was admitted to our Department complaining of headaches. His parents reported that he presented since some months ago bchavioural disturbances, with confisjon and hypersexuality. At examination we found a demented patient, blind, with 10 cranial nerve palsies nor extremities palsies. The cptic nerve discs were pale and atrophic. A CT scan (Fig. 1) showed a hypodense zone in the right temporal pole as well as in the suprasellar region. Angiographic studies revealed an aneurysm of the dorsal wall of the right internal carotid artery, after the origin of the

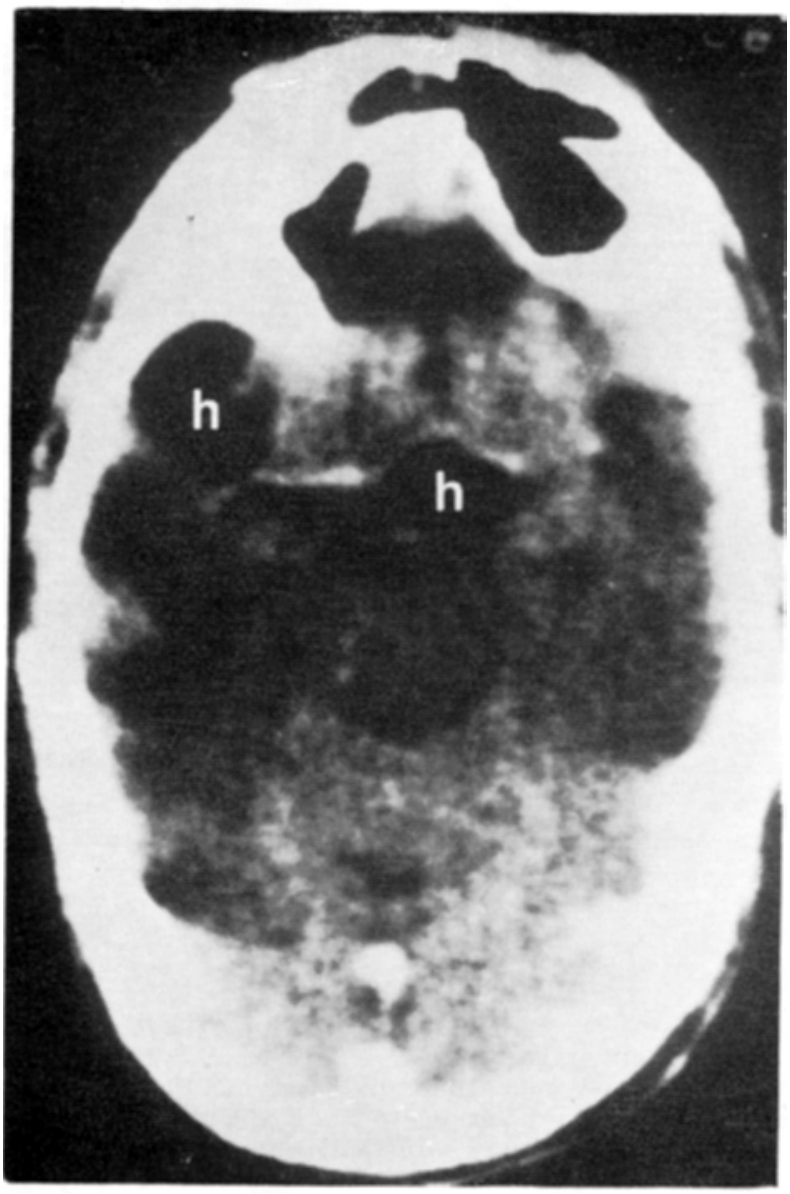

Fig. 1 - Case JRM. CT-scan exrmination showing hypodensity (h) in the suprasellar and anterior temporat region.

ophtalmic artery (Fig. 2). This aneurysm was not observed at the first angiography performed 5 years before. Considering the age of the patient and the natural history of ruptured intracranial aneurysms, the surgical treatment was indicated. The aneurysm was exposed through a right fronto-temporal craniotomy. The right temporal pole showed a cystic formation, and a severe arachnoiditis of the whole skull base was noted. An aneurysm of the dorsal wall of the ICA distal to the origin of the ophthalmic artery was found. The dome of the aneurysm was very adherent to the right optic nerve, which probably occluded it after its rupture (Fig. 3). The aneurysm was succesfully clipped with an Yasargil clip. The optic nerve and the chiasm were very thin discolored, embebed in a fibrosis with cystic formation. The cause of the bilateral amaurosis of the patient was the severe arachnoiditis produced by the subarachnoidal bleeding. Surgical lysis of the 
Fig. 2-Case JRM. Angiogrophic study of the right internal carotid. artery showing the aneurysm in the dorsal wall of this artery, between the ophthalmic and the posterior communicating arteries (arrowi.

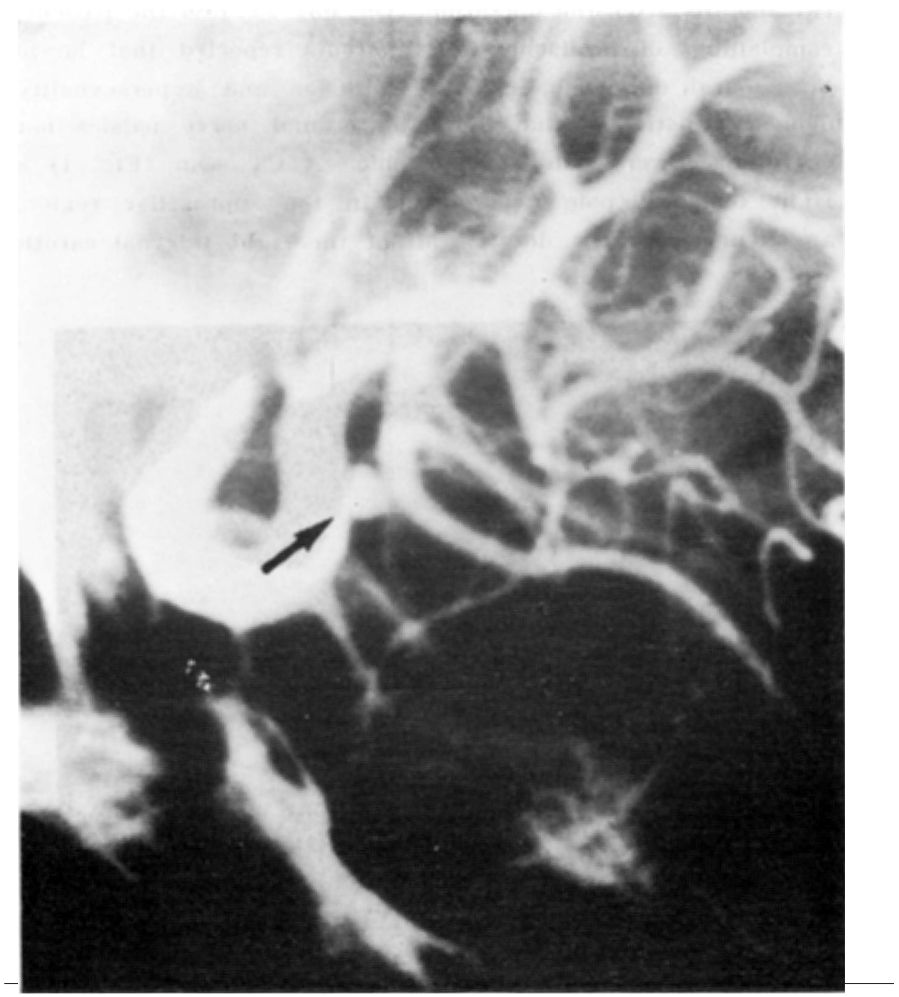

auhesions was not carried out because the patient was already blind, and it could produce additional damare to other structures at the skull base. The postoperative course was uneventfull. The patient could be discharged ten days after the operation without new reurological deficits.

\section{COMMENTS}

Optochiasmatic arachnoiditis caused by subarachnoidal haemorrhage due to rupture of intracranial aneurysms has been very seldom reported in the literature 8 . It is an inflammatory process leading to fibrosis and adhesions envolving the structures at the base of the skull. Males under 40 years of age are more frequently affected 17 . Pathological features are thickening of the arachnoid with adhesions and cystic formation filled with cerebrospinal fluid 2. The chiasm and the optic nerve may be affected with consequent atrophy of the visual fibers. This condition has nitultiple causes 4 including infections such as tuberculous meningitis 2,10,13,14, syphilis, acute and chronic meningitidis, cysticercosis 15,16 , infections of the neighbouring structures (paranasal sinuses, teeth) 3 , trauma 1 , polyarteritis nodosa 12 , intracranial bleeding 8 , foreign body reaction 7, after neurosurgical procedures (e.g. exeresis of pituitary tumors). Bleeding from intrachiasmal arteriovenous malformations usually produces sudden chiasmal visual field Ioss 8 . This haemorrhage could eventually lead to a local arachnoiditis. The symptoms are produced by inflammation, direct compression (constriction), or impairment of vascular supply to the optic fibers 3 and other neighbouring structures.

The clinical features are multiple, usually with loss of visual acuity, which presents a variable course. It may be progressive, with either monocular or binocular involvement, with progression to partial or total blindness, occurring slowly or rapidiy. Variable changes in the visual fields have been observed 5,8. Additional features are: headache, retro-ocular pain, paralysis of the extraocular muscles, nystagmus, pupilary inequality, absent corneal reflex, polydipsia, polyuria, obesity, amenorrhea, impotence, uni- 


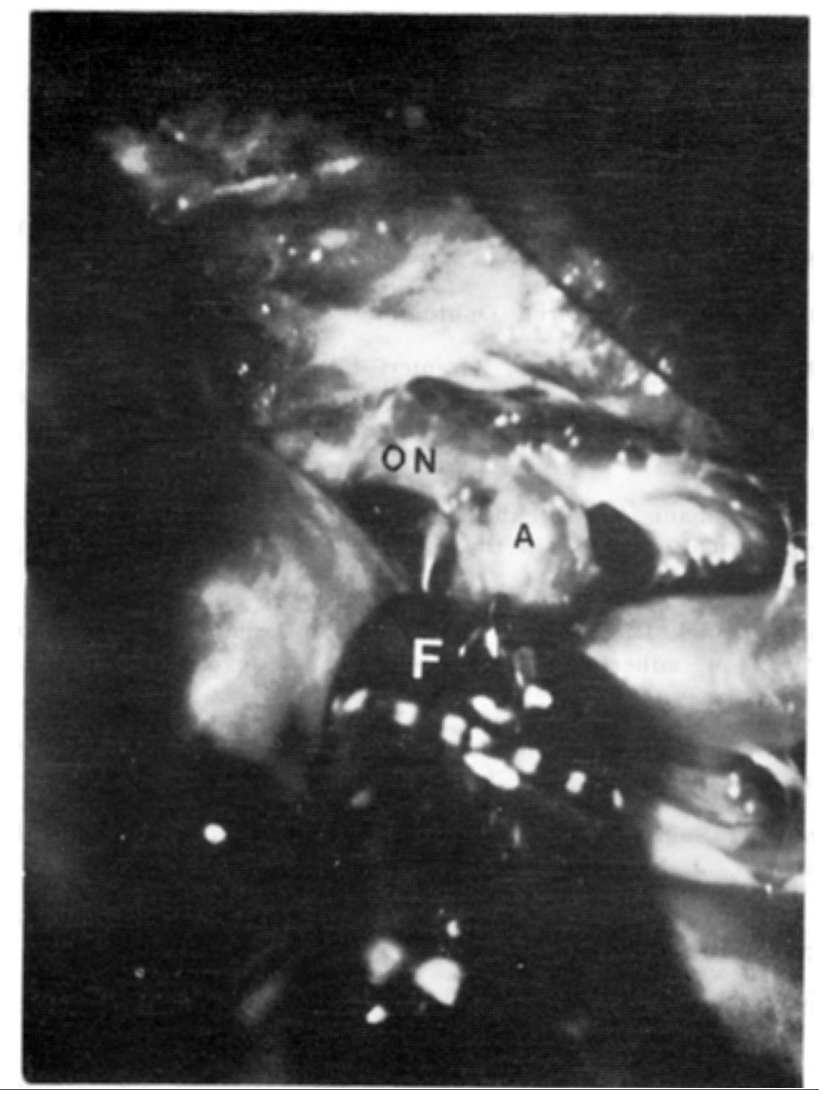

Fig. 3 - Case JRM. Operitive picture: the relationship of the aneurysm (A) to the optic nerve (ON) can be seen. $F$, forceps.

lateral or bilateral anosmia, facial paralysis, and auditory and visual disturbances 18 . The correct diagnosis is usually difficult and it is based upon the anammesis and the findings at the time of sugery. Computed tomography examination, cerebral angiography, RIHSA (radioactive human serum albubin) cisternography, pneumocisternoencephalography may be helpful, but they often fail to indicate the diagnosis 11 . The majority of intracranial saccular aneurysms are located at arterial divisions. Ohara et al. 11 described a $1 \%$ incidence for those aneurysms unrelated to arterial junctions. Aneurysms arising from the dorsal wal of the internal carotid artery are uncommon 9,20. The proximity of this kind of aneurysm to the optic nerve and chiasm may produce direct compression of these structures or, as in our case, delayed effects from the bleeding. The cause of the arachnoiditis in our case was the subarachnoidal bleeding due to rupture of this aneurysm. This could be clearly demonstrated at the operation. It is surprising that so few cases of optochiasmatic arachnoiditis caused by rupture of intracranial aneurysms have been reported in the English literature 6,8. A reason for this is not presently known. The localization of the aneurysm could be an additional factor in the etiology of this inflanmatory process. The operation of anerysms in the acute stage, with removal of clots and blood around the optic structures could eventually avoid this condition.

The treatment of optochiasmatic arachnoiditis remains controversial. Surgical lysis of the adhesions and removal of cysts in the cystic form of the disease is related to improve the symptoms only in minority of cases 8 . Dexamethasone has been used in the majority of the cases but a complete relief of the symptoms can not always be obtained. Recently, cyclophosphamide was successfully used after failure of surgical lysis of the adhesions and dexamethasone therapy 6 This diagnosis should be suspected when a patient presents progressive visual loss after subarachnoidal bleeding. Treatment should be started as soon as possible, for it can eventually avoid visual disturbances or even blindness, as it occured in our case. 


\section{REFERENCES}

1. Bodechtel G - Diagnóstico Diferencial de: las Enfermedades Neurológicas, Paz Montalvo, Madrid, 1967, pg: 646.

2. Coyle JT - Chiasmatic arachnoiditis. Am J Ophthalmol 68:345, 1969.

3. Gupta SR, Biller J, Frenkel M, Yarzagaray L - Forster-Kennedy syndrome due to optochiasmatic arachnoiditis. Surg Neurol 20:216, 1983.

4. Hartmann E - Optochiasmatic arachnoiditis. Arch Ophthalmol 33:68, 1945.

5. Iraci G, Galliyioni F, Genora M, Secchi AG, Fiore D, Zarspieri P, Rigobello L, Tomazzoli L, Pardatsches K, Marin G, Scattolin R - Optochiasmatic arachnoiditis: a review of traditional neuroradiological diagnosis (82 cases 1951-1976). Acta Neurochir (Wien) 48:151, 1979 .

6. Lavin PJM, McCrary JA III, Roessmann U, Ellenberger C Jr - Chiasmal apoplexy: hemorrhage from a cryptic vascular malformation in the optic chiasm. Neurotogy 34:1007, 1984 .

7. Marcus AO, Demakas JJ, Ross A, Duick DS, Crowell RM - Optochiasmatic arachnoiditis with treatment by surgical lysis of adhesions, corticosteroids and cyclophosphamide. Neurosurgery 19:101, 1986 .

8. McFadzean RM, Gowan ME - Optochiasmal arachnoiditis after rupture of an anterior communicating artery aneurysm. Trans Ophthalmol Soc UK 98:490, 1978.

9. Naragawa F, Shigeaki $K$, Tshiti T, Sugita $K$ - Aneurysms protuding from the dorsal wall of the internal carotid artery. J Neurosurg 65:303, 1986.

10 Navarro IM, Peralta VHR, Leon JAM, Varela EAS, Cabrera JMS - Tuberculous optochiasmatic arachnoiditis. Neurosurgery $9: 654,1981$.

11. Ohara H, Sakamoto $T$, Suzuki $J \longrightarrow$ Sclerotic cerebral aneurysms. In: Suzuki J (ed): Cerebral Aneurysms. Neuron, Tokyo, 1979, pg 673.

12. Oliver $\mathbf{M}$, Beller AJ, Behar A - Chiasmal arachnoiditis as a manifestation of generalized arachnoiditis in systemic vascular disease. $\mathrm{Br} \mathrm{J}$ Ophthalmol 52:227, 1968.

19. Schlernitzaner D, Hodges FJ III, Bagan M - Tuberculoma of the left ontic nerve and chiasm. Arch Ophthalmol $85: 75,1971$.

14. Scott RM, Sonntag VKH, Wilcox LM, Adelman LS, Rockel TH - Visual loss from optochiasmatic arachnoiditis after tuberculous meningitis. J Neurosurg 46:524, 1977.

15. Sotelo J, Cuerrero V, Rubio F - Neurocysticercosis: a new classification based on active and inactive forms. Arch Intern Med 145:442, 1985.

16 Torrealba G, Del Villar S, Tagle P, Arriagada P, Kase CS - Cysticercosis of the central nervous system: clinical and therapeutic considerations. J Neurol Neurosurg Psychiat $47: 784,1984$.

17. Vail D - Optochiasmatic arachnoiditis. Arch Ophthalmol 20:384, 1938.

18. Walsh FB, Hoyt WF - Clinical Neuro-Ophthalmology. Williams and Wilkins, Baltimore, 1969.

19. Yamuki T, Odake G. Horikawa $Y-A$ case of binasal quadrantanopsia due to optochiasmatic arachnoiditis. No Shinkei Geka 6:393, 1978.

20 Yasargil MG - Microneurosurgery, chap 2: Clinical considerations, surgery of intracranial aneurysms and results. Georg Thieme, Stuttgart, 1984. pg 33. 